\title{
Use of combined methods of treatment to obtain artificial roughness on the parts' surfaces
}

\author{
Alexander Ryazantsev ${ }^{1, *}$, and Sergey Yukhnevich ${ }^{2}$ \\ ${ }^{1}$ Voronezh State Technical University, Moskovsky Prospekt, 14, Voronezh, 394026, Russian \\ Federation, \\ ${ }^{2}$ Voronezh Mechanical Plant, Voroshilova Str., 22, Voronezh, 394055, Russian Federation
}

\begin{abstract}
Opportinities of combined treatment field of use expanding for obtaining of artificial roughness on the parts' surfaces are unveiled. The way of assurance of process stability and rise of technological parameters are shown, which allowed to expand the application field of highefficiency dimensional combined treatment with the use of precision impulse optical fiber laser as a part of laser complex. Such a task is resolved for the first time and its results contribute to creation of items of new generation of equipment, which is relevant for mechanical industry.
\end{abstract}

\section{Introduction}

At the present time the production of aerospace industry is characterized by a large range and complexity of manufactured items, at the same time manufacturing requirements to parts and assembly units are tightened. Such characteristics as flexibility and operative reconfiguration of production for manufacture of experiment articles of rocket and space equipment are coming to the fore. Under this circumstances high technology methods of combined dimensional treatment with possibility of rapid transition to processing of products of different constructions and typical sizes. Combined methods - are methods I which the process of transformation and removal of process material occurs as a result of simultaneous behavoir of two or more exposures, each performed by its own mechanism. Examples include combination of the following exposures: electrochemical and mechanical; electroerosion and electrochemical; ultrasonic and mechanical exposures; etc. Productivity of such method of treatment is usually much higher than the sum of productivities of each separate method [1]. By means of technological exposure in the surface layer such mechanical properties and retained stresses are created, that best comply with continuous and dependable service conditions. Machine parts surface quality depends mainly on the finishing treatment method and modes. To strengthen the surface layer it is required to use special treatment methods.

Importance of their consideration is resulted from the fact that surface layers of the machine parts are specifically responsible. Large number of machines performance properties such as wear resistance, contact rigidity, fatigue, corrosion resistance, contact

\footnotetext{
*Corresponding author: ryazantsev86@,rambler.ru
} 
pieces electrical and thermal resistivity, hermiticity of connections and others are determined to a large extent by contact interaction of parts which are based on the surface layers properties. Most often fatigue failure sites appear in such location. The quality of the surface layer of the machine parts, instruments and devices determines the reliability and durability of products in operation. Formation of the surface layer quality is mainly carried out during final operations of technological process of parts production.

\section{Methods of artificial roughness on the parts' surface}

Physical and mechanical properties of the machine parts surface layer are changed under the influence of compound action of force and thermal factors during the processing. During the edge (blade) tool processing force factors the prevailing influence is exerted by force factors. The result of force action use during the plastic deformation is structure destruction, rotations and displacement of crystals, work hardening of the surface layer characterized by the increase of the microhardness and decrease in viscosity. Retained stresses which, depending on treatment mode, can be positive or negative occur in the surface layer [2].

Machine part surface layer processed by the cutting tool is much different in structure and physical properties from the core of the part. The cutter pressure causes plastic deformation of tough metals (steel, copper, etc.) not only in removing chips but also in the surface layer. Sometimes the cutter destroys the structure of the surface layer to a considerable depth.

Research work on the following types of materials processing conducted at the department of "Physical and Chemical processes and technologies" of Tula State University: electrochemical processing of micro - and macro-objects; electrochemical polishing; electroerosion processing of long narrow groove; microelectroporation processing; high-speed electrolytic deposition of metals and alloys; microarc oxidation; ionic-plasma desposition; ion implantation of nitrogen etc. As a result methods of electrochemical processing of separator parts on small interelectrode gaps and with certain traveltime characteristics of electrode motion were developed and experimentally tested for the production of food and chemical engineering products with high requirements to the quality of surfaces. Electroerosion processing of long grooves in pipes of varying sections during manufacturing of techniques elements for oil and gas industry is realized [3]. Presented methods require great technological preparation of production and energy costs. In some experiments, the processed material had low strength parameters with respect to the initial material. In consequence of what it can be concluded that the use of the above mentioned methods in the rocket and space industry to obtain artificial roughness in rocket engines heat-loaded parts is not economically rational.

There are methods in which the electrothermal effect of moving cathode spots in a vacuum arc discharge is used for controlled rough surfaces. The dimensions of the roughness are governed by the current and the exposure time of the discharge, the pressure in the vacuum chamber and a number of other parameters [4]. Disadvantages of the method are a possible violation of the surface layer quality (for example, the lateral surfaces of the grooves in the heat-loaded parts), at a high energy pulse, limitation of the heat transfer area, low efficiency.

Also artificial roughness is obtained by processing the piece with electrode tool on electroerosion equipment. In this case the processing should be carried out in two stages: during the first stage, in rough mode, by means of electro-impulse method irregularities in the form of contact dimples are applied on the working part of the electrode tool, after which using finishing mode the roughness on the treated area is formed by means of electro-spark machining electrode tool [5]. Disadvantages of the method are relatively large 
wear of the electrode tool (for example, the value of wear of brass electrodes is $25-30 \%$ of the metal volume removed from the part), which significantly increases the cost of this type of processing and makes it difficult to obtain the required accuracy, requires a large consumption of energy, productivity is relatively low.

The methods analysis showed that in modern science and technology there is a need in creation of rough surfaces of metal products. One of the most effective ways to improve roughness technology is the combination of different methods of impact on the treated surface.

\section{High-performance method of combined processing for obtaining of artificial roughness of parts}

To obtain an artificial roughness a high-performance treatment method is currently being introduced into serial production, which allows to obtain parts without quality reduction of the surface layer of the product.

Combined dimensional processing method includes the processing of the part by laser method using an impulse optical fiber laser at the precision laser complex at the first stage, after which during the finishing mode finally formed artificial roughness on the surface of the workpiece is obtained by means of electrochemical treatment.

An example of this method implementation is the formation in the cooling paths of the combustion chamber shell from BrH08 TU 48-21-588-87 alloy sheet, rocket engine, the performance of the local area in the bottom of the channel for additional cooling, figures 1,2 .

For these purposes the combined methods of laser and electrochemical treatment have not been previously used. Less productive, mechanical, electroerosive and electrochemical treatments were applied, which were extremely labour-consuming and demanding essential expenses for manufacturing preparation before the beginning of works performance.

On the experimental part in composition of the workpiece on samples a physicomechanical and mechanical researches were carried out, including heat-treated condition of the part.

During the mechanical tests, a tension testing machine P5 with a heating chamber was used, during the chemical analysis process a photoelectric photometer KFK-3 and a potentiometric installation were used.

Heat treatment schedule for samples: the heating of metal up to $990^{\circ} \mathrm{C}$ with 30 minutes holding, cooling up to $600^{\circ} \mathrm{C}$, water cooling to a temperature of $20^{\circ} \mathrm{C}$.

The results are shown in tables 1 and 2.

Table 1. Results of chemical analysis of samples made from BrH0,8 TU 48-21-588-87 sheet

\begin{tabular}{|c|c|c|c|c|c|c|c|}
\hline $\begin{array}{c}\text { Content of } \\
\text { components, } \\
\%\end{array}$ & \multicolumn{7}{|c|}{ Impurities, \% } \\
\hline Chrome & Lead & Ferrum & Zinc & Magnesium & Silicon & Phosphorus & Nickel \\
\hline 0,44 & 0,003 & 0,001 & 0,003 & 0,001 & 0,006 & 0,002 & 0,001 \\
\hline
\end{tabular}

Table 2. Results of mechanical tests of samples made from BrH0,8 TU 48-21-588-87 sheet

\begin{tabular}{|c|c|c|c|}
\hline \multicolumn{2}{|c|}{ In condition of supply } & $\begin{array}{c}\text { Samples in the heat-treated state at } 20^{\circ} \mathrm{C} \\
\text { temperature }\end{array}$ \\
\hline $\begin{array}{c}\text { Percentage of } \\
\text { elongation, \% }\end{array}$ & $\begin{array}{c}\text { Strength } \\
\text { limit, } \\
\mathrm{kgf} / \mathrm{mm}^{2}\end{array}$ & $\begin{array}{c}\text { Percentage of } \\
\text { elongation, \% }\end{array}$ & $\begin{array}{c}\text { Strength limit, } \\
\mathrm{kgf} / \mathrm{mm}^{2}\end{array}$ \\
\hline 48,9 & 24,9 & 48,9 & 23,4 \\
\hline 55,6 & 25,1 & 46,7 & 23,7 \\
\hline
\end{tabular}


The obtained results lead to the conclusion that the workpieces meet the requirements of normative documentation, in particular TU 48-21-588-87 and can be used for the experiment and during the manufacture of rocket and space technology parts.

Experiments have shown that with laser power up to $50 \mathrm{~W}$, areas with a height of irregularities of $0.41 \mathrm{~mm}$ and a width of $0.82 \mathrm{~mm}$ are formed during 0.1 minutes on the working section of the part in the cooling channel.

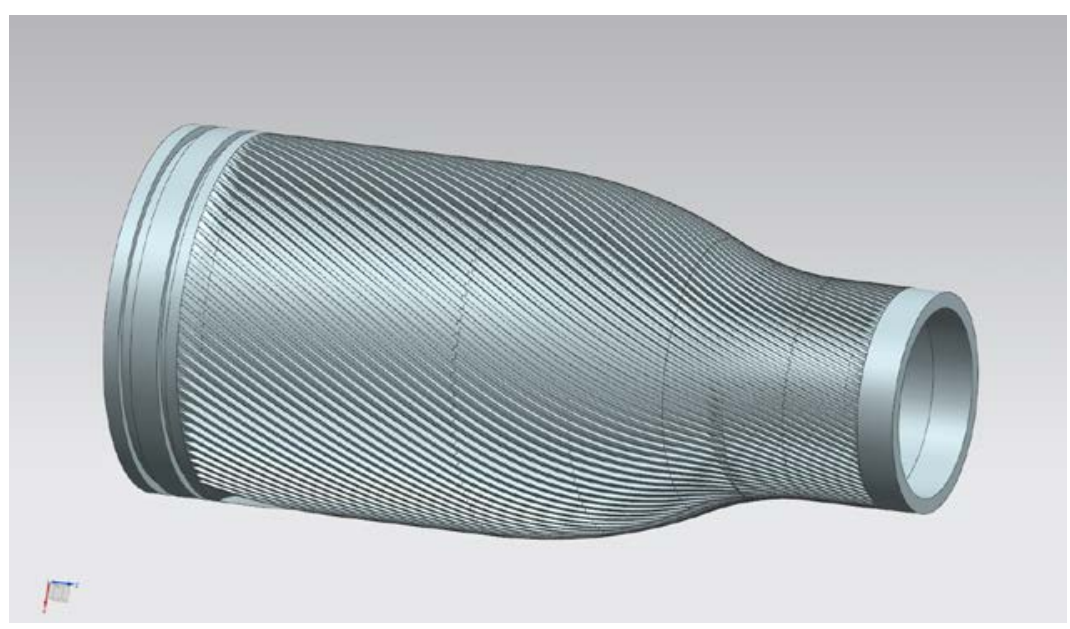

Fig. 1. General view of cooling channels after treatment

During the building up of the surface layer subject to thermal effects, it can be removed by means of electrochemical treatment using special processing modes.

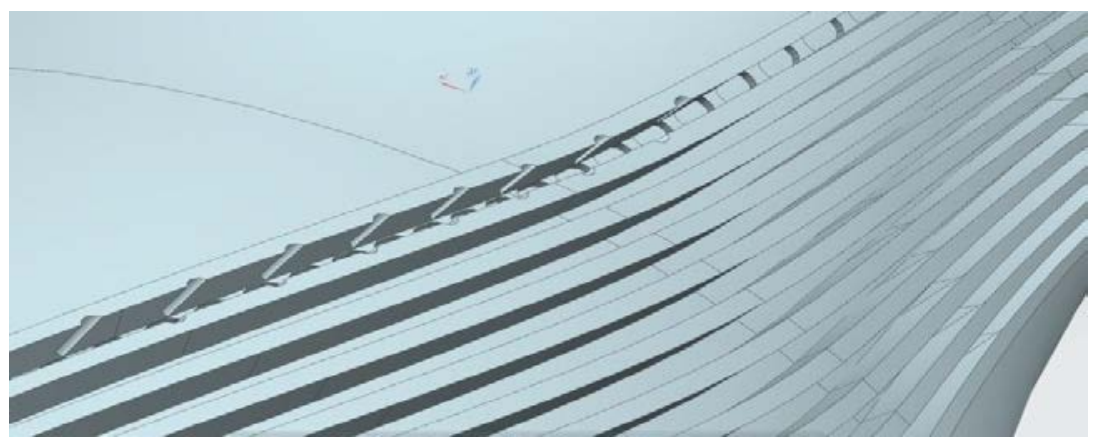

Fig. 2. General view of the shell sector with artificial roughness

For investigation of physical and mechanical properties of a material before and after the combined method processing and possible change of a material structure an additional material analysis were carried out on the samples which provided in tables 3 and 4 .

Table 3. Results of chemical analysis of samples made from BrH0,8 TU 48-21-588-87 material after application of artificial roughness

\begin{tabular}{|c|c|c|c|c|c|c|c|}
\hline $\begin{array}{c}\text { Content of } \\
\text { components, } \\
\%\end{array}$ & \multicolumn{7}{|c|}{ Impurities, \% } \\
\hline Chrome & Lead & Ferrum & Zinc & Magnesium & Silicon & Phosphorus & Nickel \\
\hline 0,49 & 0,003 & 0,001 & 0,003 & 0,001 & 0,006 & 0,002 & 0,001 \\
\hline 0,52 & 0,003 & 0,001 & 0,003 & 0,001 & 0,006 & 0,002 & 0,001 \\
\hline
\end{tabular}


Table 4. Results of mechanical tests of samples made from BrH0,8 TU 48-21-588-87 material after application of artificial roughness

\begin{tabular}{|c|c|c|c|}
\hline \multicolumn{2}{|c|}{ After treatment } & \multicolumn{2}{c|}{$\begin{array}{r}\text { Samples in the heat-treated state at } \\
20^{\circ} \mathrm{C} \text { temperature }\end{array}$} \\
\hline $\begin{array}{c}\text { Percentage of } \\
\text { elongation, } \%\end{array}$ & $\begin{array}{c}\text { Strength limit, } \\
\mathrm{kgf} / \mathrm{mm}^{2}\end{array}$ & $\begin{array}{c}\text { Percentage of } \\
\text { elongation, } \%\end{array}$ & $\begin{array}{c}\text { Strength limit, } \\
\mathrm{kgf} / \mathrm{mm}^{2}\end{array}$ \\
\hline 57 & 26,1 & 50 & 24 \\
\hline 57 & 25,4 & 52,5 & 23,9 \\
\hline
\end{tabular}

The obtained results lead to the conclusion that after the application of artificial roughness the material of the manufactured parts meets the requirements of normative documentation, change in the material structure and in properties affecting the quality does not occur. Workpieces meet the requirements of design documentation, in particular TU 4821-588-87.

Metallographic and x-ray structural researches have not revealed a violation of the surface layer quality in the channel on the finished workpiece. Measurement of the sites profile showed compliance with the requirements of technical documentation. Thus, productivity increased by about 5 times in relation to the mechanical, electroerosion and erosion-chemical processing.

The method relates to the field of mechanical engineering and can be used during the application of artificial roughness on the surface of parts, for example, on the straight and curved sections and lateral surfaces of cooling channels of the heat - loaded part - shell, which is part of the combustion chambers of the rocket engine. For these purposes the combined methods of laser and electrochemical treatment have not been previously used. Less productive, mechanical, electroerosive and electrochemical treatments were applied, which were extremely labour-consuming and demanding essential expenses for manufacturing preparation before the beginning of works performance. As a result of the suggested dimensional combined treatment, the working sections of the part in the cooling channels are obtained in accordance with the necessary technological parameters, without reduction of the surface layer quality and reliability of the product. Reduced time for technological preparation before treatment, labor intensity reduced at least for 2 times. As a result of the work, the patent №2618594 was issued, which expands the application field of the method [6].

\section{Conclusion}

Treatment by means of high-speed combined methods gives the opportunity to provide the necessary technological requirements for the part, does not violate the chemical composition of the process materials, which allows to increase the corrosion resistance of materials, improve mechanical properties and increase the service life. The obtained results allow using high-speed combined dimensional processing for manufacture of products of aviation, space and other industries from hard-to-process alloys of any geometric shape.

The result of using this method is to obtain an artificial roughness in a highperformance way, without reducing the quality of the product surface layer, with required technological parameters and expanding the application field of the method. An example of the method implementation is obtaining artificial roughness in the shell cooling channels of the combustion chamber made from $\mathrm{BrH} 08$ alloy the combustion chamber of the rocket engine. 


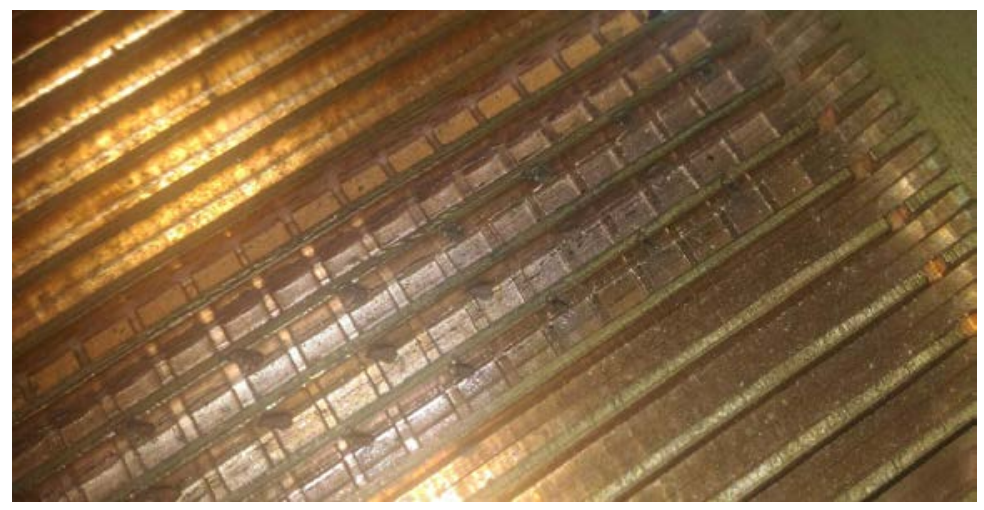

Fig. 3. Artificial roughness element obtained by the combined method of treatment

The novelty of this work is that it offers progressive methods of combined treatment for obtaining of adjustable roughness on surfaces for the first time. Working modes of treatment of parts surfaces of rocket engines details for the purpose of roughness receiving according to requirements of normative documentation are offered.

The results of this work are currently being introduced into serial at machine-building enterprises, the patent №2618594 was issued which expands the application field of the method [6].

Treatment by means of high-speed combined methods makes it possible to provide the required technological requirements to the part and does not violate the chemical composition of the processed materials, which allows to increase the corrosion resistance of materials, improve mechanical properties and increase the service life [7,8,9]. Obtained results allow to use high-speed combined dimensional processing for the manufacture of aviation, space and other industries products made from different materials and of any geometric shape.

\section{References}

1. A.Yu. Ryazantsev, O.N. Kirillov, Mechanism of finish machining by brush electrode, Voronezh State Technical University Bulletin, v.11 (5), pp. 8 - 13 (2015).

2. A.Y. Ryazantsev, M.V. Barkalov, The use of combined methods of processing during experimental testing of rocket and space equipment, Collection of articles of the VI scientific and technical conference of young scientists and specialists of the Mission Control Center, pp. $42-48$ (2016).

3. V.V. Lyubimov, V.K. Sundukov, Modern methods of electrophysico-chemical processing of micro- and macroobjects, Journal of Modern Science-Based Technologies, v 1, pp. 77-79 (2004).

4. V.N. Anikeev, M.Yu. Dokunin, Obtaining an adjustable roughness of metal surfaces in a vacuum arc discharge, Journal of Engineering Herald, v.2, pp.3-4 (2013).

5. Patent 2464137, Russian Federation, MPK V23N 5/02, Method of obtaining a local cooling section of a heat-loaded part, V.P. Smolentsev and others, №2010144769/02, announced 01.11.2010, published 20.10.2012, Bulletin № 29, 6 p.

6. Patent 2618594, Russian Federation, MPK V23N 5/02, Method for obtaining an artificial roughness on the surface of a part by a combined processing method, A.Yu. Ryazantsev, S.S. Yukhnevich, , V.A. Porotikov, №2016110651; announced 22.03.2016; published. 04.05.2017, Bulletin. 13, 4p. 
7. A.V. Pisarev, Control by technological parameters of machining by brush electrode, Nontraditional machining methods: collected works, pp.22-31 (2002).

8. O.N. Kirillov, Finish machining of transition sections by inshaped electrode, News of Orel State Technical University, edition «Basic and applied problems of engineering and technologies», v.2, pp.66-71 (2009).

9. O.N. Kirillov Development of equipment for high-velocity machining by unshaped brush electrode, Voronezh State Technical University Bulletin., v.6 (1), pp.20-22 (2010). 